\title{
Reflective functioning and personal recovery process of users with borderline personality disorder on Instagram: an explorative study using computerized and thematic analysis
}

\author{
Giovanna Esposito, ${ }^{1}$ Viviana Perla, ${ }^{1}$ Raffaella Passeggia, ${ }^{1}$ Erik Fertuck, ${ }^{2}$ Erhard Mergenthaler ${ }^{3}$ \\ ${ }^{1}$ Department of Humanities, University of Naples Federico II, Italy; ${ }^{2}$ City University of New York Graduate Center, New York, NY, USA; \\ ${ }^{3}$ Department of Psychosomatic Medicine, Ulm University, Germany
}

\begin{abstract}
Correspondence: Giovanna Esposito, Department of Humanities, University of Naples Federico II, Via Porta di Massa 1, 80133 Naples, Italy.

Tel.: +39.081.2535466 - Fax: +39.081.2535637.

E-mail: giovan.esposito@unina.it

Citation: Esposito, G., Perla, V., Passeggia, R., Fertuck, E., \& Mergenthaler, E. (2020). Reflective functioning and personal recovery process of users with borderline personality disorder on Instagram: an explorative study using computerized and thematic analysis. $R e$ search in Psychotherapy: Psychopathology, Process and Outcome, 23(3), 298-310. doi: 10.4081/ripppo.2020.463
\end{abstract}

Contributions: GE, conceptualization, writing, analyses, supervision; VP, data collection, writing, analyses; RP, writing, analyses; $\mathrm{EF}$, supervision, conceptualization; EM, supervision, analyses, conceptualization.

Conflict of interests: there are not any potential conflict of interests to declare.

Ethics approval and consent to participate: The study was conducted in compliance with the ethical guidelines for internet-mediated research (British Psychological Society, 2013), and the Declaration of Helsinki on Ethical Principles for Medical Research Involving Human Subjects. The study was approved by the Department of Humanities of the University of University of Naples Federico II, Italy, ${ }^{\circ}$ Prot. 27/2019.

The informed consent form was sent by a direct message (DM), using Instagram's instant messaging tool. The DM presented the purpose of the research, namely exploring the experience of recovery as narrated by BPD users on Instagram, through computerized and thematic analysis of shared posts. The informed consent invited the participants to disclaim any objections to include their public post in the study in an anonymous form and informed that if no objections were received, their public posts would be analysed for research purposes.

Availability of data and materials: The authors declare that the database of the present study is stored by the Department of Department of Humanities, University of Naples Federico II, Italy and that it should be shared and made available as for Journal request.

Received for publication: 3 May 2020.

Revision received: 11 September 2020.

Accepted for publication: 12 September 2020.

This work is licensed under a Creative Commons Attribution NonCommercial 4.0 License (CC BY-NC 4.0).

${ }^{\circ}$ Copyright: the Author(s), 2020

Licensee PAGEPress, Italy

Research in Psychotherapy:

Psychopathology, Process and Outcome 2020; 23:298-310

doi:10.4081/ripppo.2020.463

\begin{abstract}
Although recent literature has stated that mentalizing (or reflective functioning; RF) promoted the clinical recovery (symptomatic remission; $\mathrm{CR}$ ) of individuals with borderline personality disorder (BPD), to our knowledge, there have been no studies that analyzed the relationship between RF and a process more complex than CR, namely personal recovery (PR) - a deep and unique process of change in one's attitudes, values, feelings, goals and/or roles. Furthermore, while there have been a few studies concerning PR of BPD individuals, but to date none analyzed PR of BPD individuals through online narratives shared on social media platforms. This study investigates the relationship between RF and PR of 14 Instagram users with a selfreported diagnosis of BPD. Two groups of users were distinguished on the basis of hashtags, \#bpd and \#bpdrecovery. Seventy randomized text posts ( 5 from each user) were extracted from users' profiles: 35 from the \#bpd group and 35 from \#bpdrecovery. Two methods of analysis were applied: i) a thematic analysis, by using the theoretical framework CHIME, which identifies five dimensions of PR; and ii) a stylistic analysis of $\mathrm{RF}$ utilizing computerized reflective functioning (CRF), which identifies RF lexical markers. Results indicate that the \#bpdrecovery group presented more dimensions of PR, and that its posts showed a significantly higher RF than the \#bpd group. These findings suggest that RF could be involved in the PR of BPD individuals, thus mentalization-based treatment could be effective in supporting PR processes and enhancing the impaired $\mathrm{RF}$ in BPD users even in the online context.
\end{abstract}

Key words: Reflective functioning; personal recovery; borderline; thematic and stylistic analysis; social media.

\section{Introduction}

Borderline personality disorder (BPD) is a severe psychiatric disorder characterized by intense and unstable interpersonal relationships, marked identity disorder, and emotional dysregulation (APA, 2013). In recent years, $\mathrm{BPD}$ has received increasing research attention because of the clinical challenges that it poses and its high incidence in many health care settings (Gunderson, Herpertz, Skodol, Torgersen, \& Zanarini, 2018).

Several studies have argued that impairments of mentalizing capacity play a key role in the development of BPD (e.g., Fonagy, Luyten \& Bateman, 2015). Mentalizing, op- 
erationalized here as reflective functioning $(\mathrm{RF})$, is not a static skill or trait, but concerns "the mental process by which an individual implicitly and explicitly interprets the actions of himself and others as meaningful on the basis of intentional mental states such as personal desires, needs, feelings, beliefs and reasons" (Bateman \& Fonagy, 2004, p. 21). The mentalizing theoretical model systematizes certain traditional constructs and integrates concepts from attachment theory, cognitive psychology, psychoanalysis, and developmental psychology. Nevertheless, it may be considered a new paradigm (Freeman, 2016) offering an innovative approach that includes etiological theory, an evidence-based treatment, and developmental theory (Pothoff \& Moini-Afchari, 2013). According to some authors (e.g., Liotti \& Gilbert, 2011), although mentalizing develops within the context of safe attachment relationships, it may be fulfilled depending also on some characteristics of the social environment, such as the feeling of social security. As a multi-faceted and transversal construct, mentalizing has attracted the interest of clinicians and researchers in several contexts beyond the attachment paradigm (Fonagy, Bateman \& Bateman, 2011). However, the complexity of the construct can lead to problems related to the assessing of mentalizing, especially as part of empirical research (Gagliardini et al., 2018). For example, mentalizing has also been conceptualized as the result of four dimensions organized in eight polarities (Fonagy \& Luyten, 2009): i) automatic/controlled; ii) self/other; iii) internal/external; iv) cognitive/affective. Assessing each dimension appears to be very problematic for researchers, especially in terms of measuring those dimensions that refer to aspects of mentalizing that cannot be directly observed (e.g., implicit mentalizing), or that are difficult to convey in a coherent definition from a theoretical to a clinical perspective (Gagliardini et al., 2018). The complexity of mentalizing is also reflected in commonalities with other constructs, such as empathy, metacognition, or theory of mind; thus, some assessment problems may arise from the overlapping of mentalizing with cousin constructs (Allen, Fonagy \& Bateman, 2008).

Mentalizing has also a circular and bidirectional relationship with narration, since it is itself a narrative form. Individuals who continually mentalize create stories about their own and others' mental states (Freda \& Esposito, 2020; Freda, Esposito \& Quaranta, 2015; Freda, Gonzàlez-Monteagudo \& Esposito, 2016). Consequently, the level and quality of RF can be assessed from the individuals' narratives. For example, the Reflective Functioning Scale (RFS) (Fonagy, Target, Steele, \& Steele, 1998) is a narrative-based measure that assesses the qualities of RF by analyzing the narrative contents of Adult Attachment Interviews (AAI; George, Kaplan \& Main, 1996). Recently, a computerized text analysis measure of RF was developed: Computerized Reflective Functioning (CRF) (Fertuck, Mergenthaler, Target, Levy, \& Clarkin, 2012). As the RFS, the CRF measures RF as a unitary construct and it does not allow to measure the different dimensions that constitute mentalization. However, in contrast to content analysis, where the content is object of measurement, the innovation of CRF is to analyze the reflective, stylistic dimensions of narratives using linguistic indicators (referred to as states or psychological functions) underlying the language.

From a mentalizing perspective, BPD individuals are characterized by an impaired capacity to create a mentalizing narrative about their own and other thoughts and feelings and to preserve the coherence of self-experience (Bateman \& Fonagy, 2008). In order to enhance RF in BPD individuals, the Mentalization-Based Treatment (MBT) was developed, the effectiveness of which was supported by randomized controlled trials (Bateman \& Fonagy, 2008). However, according to Fonagy and Bateman (2008), an improvement of RF may be conceived to be a good outcome of any therapy for BPD, regardless of the treatment model. Indeed, several studies document increases in RF after psychodynamic psychotherapies that were not specifically mentalization-based (Levy et al., 2006). For example, in a recent study, De Meulemeester, Vansteelandt, Luyten, \& Lowyck (2018) showed that a long-term hospitalizationbased psychodynamic treatment was associated with significant increases of RF in individuals with BPD. Evidence suggests that RF may be a mediator of therapeutic change, predicting certain global changes after treatment (Muller, Overbeck \& Grabhorn, 2006), while low RF also seems to correlate with the severity of many BPD symptoms (Fonagy, Luyten \& Bateman, 2015).

Overall, studies have underlined the importance of the relationship between RF and the processes of symptomatic remission or reduction (Antonsen, Johansen, Rø, Kvarstein, \& Wilberg, 2016), also known as the process of clinical recovery (CR; Maone \& D'Avanzo, 2015). Nevertheless, to our knowledge, no studies have analyzed the role of $\mathrm{RF}$ in a process more complex than $\mathrm{CR}$, namely personal recovery (PR). The concept of recovery is somewhat controversial, since the literature on recovery has been oriented by two contrasting paradigms: recovery as a clinical outcome, namely a functioning condition evaluated according to clinical standards; and recovery as a personal process, centered on the patient (Slade, 2009). The first paradigm (CR) was developed in the medical tradition: from this perspective, a person would be considered "recovered" if the symptoms of her mental illness were reduced or disappeared. But in the 1980s, the mental health users' movement advocated a new vision of recovery, which was described as "a deeply personal, unique process of changing one's attitudes, values, feelings, goals and/or roles" (Anthony, 1993, p. 527). According to Borg and Davidson (2008), PR references concepts such as personal empowerment, self-expression overcoming the social stigma of mental illness, living a satisfying life despite any limitations of illness. The main goals of individuals in the PR process are the development of a posi- 
tive identity, the ability to manage symptoms and effects of the illness, and the construction of appreciable social roles (Slade, 2009).

One of the main contributions to research on PR is the metanalysis by Leamy, Bird, Le Boutillier, Williams, \& Slade (2011), who responded to the need for an empirical basis for research and recovery-oriented practices. As PR is conceived as a list of personal outcomes, namely measurable dimensions of change, which typically occur during the process, Leamy et al. (2011) identified the most relevant dimensions of PR in both clinical research and practice: Connectedness, Hope and optimism about the future, Identity, Meaning in life, and Empowerment (CHIME). "Connectedness" refers to the interpersonal relationships which support the individuals in specific challenges of their mental illness. "Hope and optimism" are related to motivational aspects, such as positive thinking and optimistic attitudes towards future changes. "Identity" refers to the process of redefining dimensions of personal identity on the basis of personal elaborations of the mental illness. "Meaning of life" refers to developing a new sense and purpose in one's life, beyond the effects of mental illness. Finally, "Empowerment" refers to assuming control over one's life and personal responsibility. According to Ridgway (2001), hope is conceptualized as the first factor to emerge in PR process, almost inexplicably. Corrigan (2002) argued that empowerment has a strong impact on PR goals, by replacing self-stigmatizing attitudes with positive expectations about life.

A large number of studies have been conducted on PR considering a wide range of mental disorder diagnoses. Some have focused specifically on the PR of people with personality disorders (Sheperd, Sanders, Doyle, \& Shaw, 2016). Nevertheless, with regards studies specific to recovery of BPD individuals, a review by $\mathrm{Ng}$, Bourke and Grenyer (2016) found that most of the current literature focused only on CR; only a few qualitative studies explore PR in BPD individuals (Holm \& Severisson, 2011; Katsakou et al., 2012; Laviriere et al., 2015). At the heart of these studies on the PR of borderline individuals are firstperson narratives and interviews with people with mental illness, collected in different contexts such as by mental health services (Topor, Borg, Di Girolamo, \& Davidson, 2011). Naslund, Aschbrenner, Marsch, \& Bartels, (2016) showed that people with mental illness share their personal experiences of illness also through other media, such as social media platforms. To our knowledge, no studies analyzed the PR process of BPD individuals in online narratives shared on social media platforms. We suggest here that narratives shared online may be useful to analyze the PR of people with a mental illness (Lamarre \& Rice, 2017), including BPD.

\section{Online recovery}

Following Naslund et al. (2016), Birnbaum, Rizvi, Correll, Kane, \& Confino, (2017) demonstrated that popular social media platforms, such as Facebook, Instagram and Twitter, are used almost universally by young people with severe mental illness. It is now possible to access multimedia versions of these narratives, through the proliferation of online personal profiles concerning mental illness experiences and processes of change. According to Jiang, Bazarova, and Hancock (2011), people may engage in more intimate self-disclosure in online settings than offline. Kingod, Cleal, Wahlberg, \& Husted (2016) showed that people with chronic illness increasingly use online settings to tell stories of their psychological experiences.

The evidence demonstrates that social media can serve attachment functions, particularly for users with attachment anxiety (Oldmeadow, Quinn \& Kowert, 2013). Regarding the relationships between social media use and RF, studies had contrasting results. On one hand, one recent study found that the individuals with higher levels of RF made less use of social media: for example, they share fewer selfies (Adler, 2017); on the other hand, a neuroscientific study (Turel, He, Brevers, \& Bechara, 2018) suggested that the brain structures involved in social-semantic and mentalizing tasks (e.g., seeing, identifying and classifying more faces, etc.) may be linked to the extent of social media use, in this case, Facebook. Other studies have focused on the use of social media in BPD individuals. As Jinnie, Michael, Sakari, Butterfill, and Lukasz (2020) stated, individuals with BPD traits prefer a greater engagement through social media use than the general population; in fact, individuals with higher BPD traits reported posting more often on social media and giving more importance to social media in their social behaviors and daily routines.

According to Naslund, Grande, Aschbrenner, and Elwyn (2014), the decision to go on social media can be a turning point in the course of mental illness, since it allows people to share and face the stigma of mental illness, to find hope and support from other users, and to narrate resilience stories in order to develop coping strategies. For example, some researchers focus on pro-recovery content shared online by people with eating disorders or with selfharm behaviors (Margherita \& Gargiulo, 2018). These studies focused on contents that encourage PR, such as sharing stories and advice related to mental health management. Furthermore, some social media platforms seem to emerge as alternatives to pro-anorexia websites, which promote instead a collective identity based on symptoms (Smahelova, Drtilova, Smahel, \& Cevelicek, 2019). Therefore, social media platforms can allow access to a subjectively constructed view of phenomena like PR in people with mental illness (Lamarre \& Rice, 2017). For example, Instagram is a popular image based social network site (SSN) launched in 2010; Instagram-based research has been increasing over the past few years, and studies of mental health-related issues on these platforms has become more frequent (Bogolyubova, Upravitelev, Churilova, \& Ledovaya, 2018). Instagram is currently the most popular social network among young people, with a 
slight majority of female users (Bogolyubova et al., 2018). Posts on Instagram are based on static images such as selfies (Boursier \& Manna, 2018) or short videos, which the user may accompany by text and/or hashtags: words preceded by "\#” used to categorize the content of the post. Among the several communication tools available on social platforms, the hashtag has proven to be the most powerful method of sorting, finding, and organizing contents (Daer, Hoffman \& Goodman, 2014), and of orienting the perspective of reading shared posts (Olszanowski, 2015). Hashtags not only gather contents but may also bring together users who belong to stigmatized groups, such as sexual and racial minorities and mental illness sufferers (Naslund et al., 2019). That is, the hashtag may create social connections and develop online communities (Khosravinik \& Unger, 2016) thanks to its identity function: users identify themselves with values related to the hashtag itself (Konnelly, 2015). This phenomenon is particularly notable in online identities related to mental illness (Andalibi, Ozturk \& Forte, 2015). Mental health-related studies conducted on Instagram have relied mainly on content analyses of images (Andalibi et al., 2015; Reece \& Danforth, 2017). However, as shown by Pillai (2019), the texts of posts not only describe the image, but propose a narrative context for shared content. This narrative dimension contributes to the generation of a coherent self-experience among social media users.

\section{Aims and hypothesis}

The general aim of this study is to analyze the reflective style of texts connected to posts shared on Instagram (hereafter posts) by users with BPD and to investigate any relationships to a user's $P R$ process.

To reach this aim, we propose to achieve the following specific objectives: i) to analyze PR processes in the posts; ii) to measure the reflective style of the posts.

Posts were identified by the hashtags "\#bpd" or "\#bpdrecovery" applied by the users to posts shared in Instagram.

As stated above, no studies on RF and PR of borderline users in an online setting have been conducted; thus, we did not base our hypotheses on specific empirically demonstrated relationships, but on the following relevant findings reported in the literature: the recognized identity value of hashtag on the SSN (Andalibi et al., 2015; Konnelly, 2015); the role of hope as an early emerging aspect of PR (Ridgway, 2001); the empowering feature of the online context for people with mental illness (Naslund et al., 2014); and the recognized role of $\mathrm{RF}$ as a mediator of change processes for BPD individuals (Fonagy et al., 2015).

We expect that the hashtag will distinguish between two groups: specifically, the posts of the "\#bpdrecovery" hashtag group will show all the dimensions of PR, while the posts of the "\#bpd" group will show only dimensions of hope and empowerment. Moreover, we expect that the posts of \#bpdrecovery group will present a higher reflective style (i.e., greater RF).

\section{Materials and Methods}

\section{Participants}

The personal profile of the second author was used to $\log$ onto the Instagram social network. Instagram was chosen because, according to Jinnie et al. (2020), it is one of the social media used most frequently by people with borderline traits. By following the suggestions of Coppersmith, Dredze, Harman, \& Hollingshead (2015), we selected keywords which comprised common words and terms that are used online to refer to the diagnosis of BPD, not only the labels typical of DSM-5 (APA, 2013): specifically, we used these keywords to form the hashtags: "\#bpd", "\#bpdrecovery", "\#borderlinepersonalitydisorder", "\#borderline." We searched English hashtags to reach users of different nationalities who had chosen to publish posts in English to expand their online social network.

The inclusion criteria in the sample of the present study were: i) to be at least 18 years old; ii) to be an active user (i.e., a user who has at least 30 followers and 60 profile photos) who is not an organization, a brand nor spammer (Hu, Manikonda, \& Kambhampati, 2014); iii) to have disclosed a diagnosis of BPD; iv) to have reported being in contact with a mental health service (e.g., as an outpatient, inpatient and utilizing private services).

The informed consent form was sent by a direct message (DM), using Instagram's instant messaging tool. The DM presented the purpose of the research, namely exploring the experience of recovery as narrated by BPD users on Instagram, through computerized and thematic analysis of shared posts. Moreover, the informed consent invited the users to disclaim any objections to include their public post in the study in an anonymous form and informed that if no objections were received, their public posts would be analysed for research purposes.

Requests to participate, along with informed consent forms were sent to 35 BPD users who reached the inclusion criteria. Our final sample consisted of 14 BPD Instagram users (females $=12$; males $=2$ ). Then, such users were divided in two groups, of 7 users each (female $=6$; male=1), based on the use of two hashtags: \#bpd, that is, which identified users who recognized themselves as having BPD, and \#bpdrecovery, which identified the users who recognized themselves as having BPD and also in a process of recovery. Users' Instagram profiles were analogous to a diary composed of posts classified by hashtags, updated with variable frequency; posts concerned the self, relationships and emotions, the management of the mental illness, and the use of mental health services.

\section{Ethical issues}

The study was conducted in compliance with the ethical guidelines for internet-mediated research (British Psychological Society, 2013), which preserved the anonymity of Instagram users, hiding their names, nicknames, profile ti- 
tles and editing texts. A request for informed consent was sent to the participants who met the inclusion criteria. In order to avoid affecting the social network usage habits, we gathered posts that had been shared in the three months preceding the receipt of informed consent. All data were processed in compliance with current privacy laws (Article 13, General Data Protection Regulation, 679/16). Moreover, the study was conducted in accordance with Italian law, the ethical guidelines of the Italian Association of Psychology (AIP), and the Declaration of Helsinki on Ethical Principles for Medical Research Involving Human Subjects. The study was approved by the Department of Humanities of the University of University of Naples Federico II, Italy.

\section{Measures}

\section{CHIME Recovery Framework}

To analyze the posts, the theoretical framework CHIME was adapted for use with online text. CHIME identifies five dimensions of PR. As stated above, connectedness refers to the social network supporting the recovery journey. The support of interpersonal relationships is crucial as it promotes, through reciprocity and equality, agency and self-efficacy during the PR. Hope and optimism are defined as key ingredients of PR: they refer to belief in the possibility of improvements and positive expectancies of the future. Identity refers to rebuilding a positive sense of identity: from an identity based only on the mental illness to an identity that makes mental illness only one of its possible dimensions. Meaning of life consists in being able to direct the aspects of one's own life in an adaptive way, by integrating the mental illness into one's life experience. Finally, empowerment refers to the assumption of an active position that allows people to decide autonomously and to take risks and responsibilities.

According to the CHIME recovery framework, these five dimensions may be considered first-order themes that occur across multiple research contexts (Brijnath, 2015; Piat, Seida \& Sabetti, 2017). Nevertheless, the original version of CHIME additionally contains second-order themes (Leamy et al., 2011). According to Brijnath (2015), the specific features of the research context mediate how second-order themes of CHIME are to be operationalized. Therefore, in this study, we aim to track first-order themes of CHIME as theory-driven criteria to be found in our sample; we adopted a data-driven approach to track some second-order themes related to the specificity of our narrative sample.

Table 1 shows the definitions of first-order themes and various examples of narrative extracts that sample narrative markers.

\section{Computerized reflective functioning}

Although useful and reliable in clinical studies, the RFS is expensive and laborious, requiring raters with specialized skills. To overcome these limits, the Computerized Reflective Functioning (CRF) was developed: a computer-driven text analysis that measures the stylistic dimension of reflective functioning (RF) by calculating the frequency of some linguistic markers (Fertuck et al., 2012). It is built through the marker approach (Mergenthaler, 1996; Mergenthaler \& Bucci, 1999) - a procedure based on a stylistic model that transforms a previously validated manual coding system into a computerized text scoring method, utilizing dictionaries composed of markers: discrete linguistic indicators (rather than semantic content markers) that refer to states or psychological functions underlying the language (Mergenthaler, 1996). CRF is not difficult to use, it is timeefficient and cost-effective since it can be used with a large amount of data and does not require specialized training: previous studies have successfully adopted it to analyze the transcripts of psychotherapy sessions (Boldrini et al., 2018; MacIntosh, 2017).

CRF can also be applied to interviews and other linguistic data, even to text samples of at least 50 words (Fer-

Table 1. Definitions and examples of the CHIME First-order themes.

\begin{tabular}{|c|c|c|}
\hline First order theme & Definition & Example \\
\hline Connectedness & $\begin{array}{l}\text { It refers to different relationships which support } \\
\text { people who are in the journey of recovery }\end{array}$ & $\begin{array}{l}\text { My parents have always been there for me when I've } \\
\text { struggled, and I value them both very much }\end{array}$ \\
\hline Hope and optimism about the future & $\begin{array}{l}\text { It refers to believing in the possibilities of recovery } \\
\text { and to considering the future with positive expectancy }\end{array}$ & $\begin{array}{l}\text { I'm relieved and hoping that I can get the right } \\
\text { treatment and care for me to live my best life }\end{array}$ \\
\hline Identity & $\begin{array}{l}\text { It refers to the process of redefining identity: from an } \\
\text { identity based only on the illness to an identity that } \\
\text { integrates it }\end{array}$ & $\begin{array}{l}\text { I am worrying only about the things that makes me } \\
\text { unique. My uniqueness is what makes me important. } \\
\text { My qualities of good (and sometimes bad) made me } \\
\text { what I am }\end{array}$ \\
\hline Meaning of life & $\begin{array}{l}\text { It refers to being able to direct the aspects of one's life } \\
\text { in an adaptive way, despite the illness }\end{array}$ & $\begin{array}{l}\text { I am living proof that even though you live with these } \\
\text { illnesses you can still have a (kind of) functioning life }\end{array}$ \\
\hline Empowerment & $\begin{array}{l}\text { It refers to taking an active position that allows to be } \\
\text { agentive and responsible }\end{array}$ & $\begin{array}{l}\text { It takes being strong and not giving up, and pushing } \\
\text { through what is not easy, if you want a change you will } \\
\text { have to make certain adjustments and work hard to } \\
\text { make sure you see a change }\end{array}$ \\
\hline
\end{tabular}


tuck et al., 2012). CRF uses two dictionaries, CRF High and CRF Low, that are composed of the most frequent words extracted by AAIs (George et al., 1996). In previously studies, the CRF High dictionary significantly correlated with human-rated RF scores in both a clinical sample of individuals diagnosed with BPD (Spearman's $r h o=0.57 ; \mathrm{P}=0.0001)$ and a nonclinical sample (Spearman's rho $=0.57 ; \mathrm{P}=0.002$ ). However, the addiction of the CRF Low dictionary did not significantly increase the correlation between CRF and RF (Fertuck et al., 2012). For this reason, CRF Low was not considered to be a reliable measure to assess RF.

CRF High is composed of 54 markers; CRF Low is composed of 49. Some of the High CRF word markers are quite common words (e.g., and, was, that, know, etc.), which might not seem to be associated with the RF construct. However, these words are related to aspects, such as narrative coherence and references to the past, that do connect to reflective functioning (Fertuck et al., 2012). To analyze the reflective style, the computer program of CRF calculated four indices: i) "TOT": total number of words in the text; ii) "CRF": frequency of markers included in the vocabularies High and Low; iii) "CRF High": relative frequency of the markers High on the total number of words in the text; iv) "CRF Low": relative frequency of the markers Low on the total number of words in the text.

\section{Procedures}

\section{Data collection}

We have gathered 502 posts shared on Instagram by the 14 users between May 1 and July 28, 2018. To use the CRF software, texts must contain at least 50 words, so we excluded shorter posts. Following these criteria, a total of 221 posts (averaging 15 posts per user) were collected and progressively numbered. From these 221 posts, 70 posts (5 per user) were randomly extracted to be analyzed both with CRF and CHIME. We chose to extract 5 texts to ensure that all users' posts were equally represented to be randomized (for one user we collected 10 posts in our time window). The randomization procedure was based on the generation of random numbers in Excel.

\section{Data analysis}

To reach the first objective of the study, we performed a thematic analysis using a mixed approach: a theory-driven method (in order to track the first-order themes of CHIME) (Leamy et al., 2012) was combined with a data-driven one (in order to generate second-order themes connected to the specific research questions). As argued by Denzin and Lincoln (2005), the combination of these two approaches ensures a high level of theoretical consistency and grounds hypotheses on empirical data. Both theory- and data-driven methods allowed focus on the relevant dimensions (firstorder themes) as they are conceptualized in the literature, but at the same time they allowed preservation of the complexity of specific second-order themes linked to the narrative context on examination (Denzin \& Lincoln, 2005). Inspired by the procedure suggested by Shepherd (2016), we adopted various descriptive codes to extend understanding of second-order themes. The CHIME recovery framework was used to identify the different ways in which dimensions of PR occurred in the two groups: the unit of analysis was the narrative extract, so every post of each user could contain more than one theme, since it was composed of more than one narrative extract.

The analysis was conducted by the second and third authors of this article. First, both researchers read all the gathered posts. After this initial reading, the researchers separately adopted the theory-driven approach by tracking the first-order themes, verifying their presence or absence. They then compared the results of this first level of analysis, calculating Cohen's Kappa (Cohen, 1960). Secondarily, each researcher defined separately a list of potential second-order themes, which were also shared to see if a consensus agreement could be made about specific labels and the frequency of each second-order theme. During this step, when it was necessary, descriptive codes were selected from the list in order to explain the specificities of second-order themes in the narrative samples. In the last steps of the analysis, in cases of disagreement between these two researchers, a third judge (i.e., the first author) intervened. At the end of the thematic analysis, a Fisher's exact test was performed to assess any differences in frequency distributions of each first-order theme between the two different groups (\#bpd, \#bpdrecovery).

To reach the second objective of the study, we executed a stylistic analysis of the reflective style using CRF (Fertuck et al., 2012). All of the 70 posts were formatted according to CRF standards. We first transformed all words into lower case, then took out all parentheses and standardized slang words (e.g., changing "cuz" to "because").

A non-parametric Mann-Whitney U test for independent samples was performed to estimate if there was a statistically significant difference between the distributions of CRF High scores between the \#bpd and \#bpdrecovery groups. As stated above, according to Fertuck et al. (2012), the index CRF Low is not a significant measure for assessing RF because of its small correlation with RFS scores; thus, we performed analyses only on CRF High indexes.

\section{Results \\ CHIME analyses}

The following first- and second-order themes emerged from the analysis of the posts. Cohen's kappa (Cohen, 1960) for the first-order themes showed a high agreement between researchers (Cohen's $k=0.92$ ).

We will present the description of results below separately for each PR theme. Below, a summary table 
(Table 2) reports the occurrences of each theme, the descriptive codes and the p values of the Fisher's exact test.

\section{Connectedness}

The first-order theme of connectedness has been found in both groups of users with a total frequency of 15 narrative extracts (hereafter n.e.) - indeed, no statistically significant difference emerged between the two groups $(\mathrm{P}=0.60)$. Secondary themes related to the connectedness process were identified as offline versus online relationships. Specifically, offline relationships emerged in both groups (n.e.=11), with different qualities, but online relationships emerged only in \#bpd posts (n.e.=4). Two different descriptive codes were proposed to describe the offline relationships: the other who recognizes and the other as an enemy. The \#bpdrecovery group described offline relationships as supportive. Users talked about the support perceived by the others, the feeling of being recognized, and gratitude to those who 'saw' and understood them. Being recognized was narrated as occurring in different offline contexts and as concerned different aspects of the self. A\#bpdrecovery user wrote about a person who recognized her "worth and not her illnesses." Another \#bpdrecovery user referred to the support received by mental health services: "Finally 20 years later they heard me ... I was recognized in my emotions!"

On the other hand, the offline relationships of the \#bpd group were full of blame. The 'other' was devalued and accused, and relationships became the place where fights happened. The other, then, often became an enemy. A \#bpd user wrote about his sentimental relationship: "In real life, if you're viciously on opposite sides and taking things personally ... you are enemies [...] if you are my enemy, I will not have empathy for you because you have chosen a path which is no responsibility of mine." Health services were also devalued and criticized for policies related to taking charge. A user told about his visit to the psychiatric hospital: "I then begged him to help me, he went off to speak to the consultant, came back and said no, we won't admit you as we haven't got the therapies you need [...] he then said that if I need help to come back, why would I do that when you won't help me?"

Instead, regarding the second-order theme of online relationships, we proposed a descriptive code that is the other who is idealized. A \#bpd user wrote about his online relationships: "You're stronger than you think. Today and every day. You're superheroes in my eyes. Thanks for being so damn brave and weathering this storm with me."

\section{Identity}

Identity was a theme that occurred in the posts of both groups with a total frequency of 18 n.e. This theme was significantly more frequent $(\mathrm{P}=0.048)$ in the \#bpdrecovery group than in \#bpd group. The two second-order themes that emerged were: identity in progress (n.e. $=15$ ) and identity as a symptom (n.e.=3). Identity in progress emerged in the posts of both groups, but with a higher frequency and a greater complexity among the \#bpdrecovery group (n.e.=13); but, identity as a symptom emerged only in the \#bpd group.

In posts from the \#bpdrecovery group, some stories about the efforts to build a more coherent sense of self emerged. Users seemed to be taking the first step in building an identity which may be an alternative to one based on mental illness. It also emerged that users had taken a critical position towards symptoms in order to become 'something more' than the diagnostic category. For example, a \#bpdrecovery user said: "I'm having to do the opposite of what my mental illness wants me to do but I'm trying and I'm proud of that!' In some posts it also emerged that the decision to undertake a recovery process was a turning point towards the rebuilding of fragmented parts of the self. One \#bpdrecovery user wrote: "I am starting to see few broken parts of myself that I didn't see ever. I'm not only this."

In contrast, \#bpd users based their identity mainly on the mental illness as a way to give meaning to their lived experience. Diagnoses and associated symptoms seemed to be able to explain every aspect of life. A \#bpd user

Table 2. CHIME themes and descriptive codes, frequencies of narrative extracts (n.e.) and Fisher's Exact test P-values in \#bpdrecovery and \#bpd groups.

\begin{tabular}{|c|c|c|c|c|c|c|}
\hline First-order themes & n.e. & Second-order themes & Descriptive codes & \#bpdrecovery & \#bpd & $\mathbf{P}$ \\
\hline \multirow{3}{*}{ Connectedness } & \multirow{3}{*}{15} & Offline relationships & The other who recognizes & 6 & l & \multirow{3}{*}{0.600} \\
\hline & & & The other as enemy & ' & 5 & \\
\hline & & Online relationships & The other who is idealized & 1 & 4 & \\
\hline \multirow[t]{2}{*}{ Identity } & \multirow{2}{*}{18} & Identity in progress & & 13 & 2 & \multirow{2}{*}{0.048} \\
\hline & & Identity as a symptom & & / & 3 & \\
\hline Hope and optimism about the future & 12 & & & 8 & 4 & 0.190 \\
\hline \multirow[t]{2}{*}{ Empowerment } & \multirow{2}{*}{7} & Individual empowerment & Engagement & 4 & l & \multirow{2}{*}{0.007} \\
\hline & & Social empowerment & Fight against the stigma & 3 & / & \\
\hline
\end{tabular}

l


wrote: "I feel like the only identity I have are my mental illnesses, [...] I was diagnosed with anxiety so therefore I'm anxious, it's like the only facts I have and know to be true." Another \#bpd user wrote in a post: "The issues I end up having because of my identity disorder... I am constantly fighting my own identity cage."

\section{Hope and optimism}

Hope and optimism emerged in both groups and were identified in a total of 12 n.e. No significant difference was found between the groups $(\mathrm{P}=0.19)$ and no secondorder themes emerged from the analysis. In both groups, there was a realistic optimism, with an even higher frequency in the \#bpdrecovery posts (n.e.=8). Hope and optimism seemed to be a motivation to change despite failures, which were characteristic of an uneven and uncertain journey such as recovery. Hope helped to take on the challenges of everyday life for individuals with BPD, such as the relapses into dysfunctional behavior. A \#bpdrecovery user, for example, told about her experience of failure during a week off from therapy as such an event: "To see how you go and explore what areas you need to work on more." In a similar way, a \#bpd user told about her efforts to repair current relapses in the future: "I am trying to repair it and repairing it starts with my behavior and actions [...] I'm also going to try to be more present."

\section{Empowerment}

We identified 7 n.e. that referred to the first-order theme of empowerment, but only in the \#bpdrecovery group. A Fisher's exact test confirmed that empowerment was significantly more frequent $(\mathrm{P}=0.007)$ in the $\# b p-$ drecovery than in the \#bpd group.

We identified two distinct second-order themes from \#bpdrecovery group: individual (n.e. $=4$ ) and social (n.e.=3) empowerment. We proposed a descriptive code to explain the second-order theme of individual empowerment: engagement. This referred to the engagement of individuals in the \#bpdrecovery group through adopting strategies to manage their mental illness. One \#bpdrecovery user wrote: "I'm learning each day how to change my thinking habits [...] That's what's going to be right for me." It seemed that users gave a transformative value to involvement in the management of the mental illness because it allowed them to feel responsible for their own improvement.

The second-order theme of social empowerment emerged with reference specifically to the online community. This especially concerned the fight against the stigma of mental illness. Fighting this stigma emerged as a dimension of agency regained by the online community. The online context gave visibility to challenging the stigma as well as stereotypes about life with a mental illness. For example, one \#bpdrecovery user told about the power of sharing online resilience stories in order to give advice on coping strategies and how to fight stigma:
"There's a lot of work needed in mental illness and suicide but with more of us willing to talk openly and honestly we can create that change, we can help those who don't understand maybe understand a little more!"

\section{Meaning of life}

In neither of the groups did n.e. about the meaning of life emerge; thus, no posts told about the ability to direct life in an adaptive way and integrate the experience of mental illness into everyday life.

\section{Computerized reflective functioning analysis}

Descriptive analyses of the 35 posts of the \#bpd and 35 posts of the \#bpdrecovery groups showed that the \#bpdrecovery group had longer texts $(\bar{x}=175.74 ; S D=44.24)$

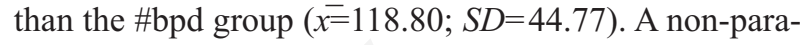
metric Mann-Whitney U test for independent samples was performed, which found the difference between the two groups in length of texts to be statistically significant $(\mathrm{P}=0.04)$. To correct post length, $\mathrm{CRF}$ measures ( $\mathrm{CRF}$, CRF High) were multiplied by the natural logarithm of the respective text length $(\ln (\mathrm{n}))$ for each single text following Fertuck et al. (2012). The CRF High index, corrected for length, was higher in the \#bpdrecovery group $(x=1.27 ; S D=0.10)$ than in the \#bpd group $(x=1.05$; $S D=0.13$ ). A Wilcoxon test for independent samples showed a significantly higher CRF High index in the \#bpdrecovery than in the \#bpd group $(Z=2.55 ; \mathrm{P}=0.01)$.

\section{Discussion}

The thematic analysis partially confirmed our first hypothesis. On one hand, the hashtag distinguished the groups in important ways: the \#bpdrecovery group presented more dimensions of PR than the \#bpd group, specifically four of the five CHIME dimensions of PR: connectedness, hope, identity, and empowerment. The \#bdp group presented only 3: connectedness, hope, and identity. Furthermore, the dimensions of identity and empowerment were significantly more frequent in the \#bpdrecovery group. However, meaning of life did not emerge in \#bpdrecovery as predicted (nor in \#bpd), and, also in contrast to expectations, the empowerment dimension did not emerge in \#bpd group.

The \#bpdrecovery group seemed to be involved in an identity rebuilding process, trying to contrast the feelings of a fragmented self, while the \#bpd group seemed to be passively accepting their diagnosis. We know from the literature that rebuilding a positive identity is a central component of PR (Sheperd et al., 2016). On the contrary, the internalization of mental illness as a basis for identity can affect the concept of the self and make the process of PR more complex (Estroff, Lachicotte, Illingworth, \& Johnston, 1991). The \#bpdrecovery group seemed to be at a later stage of their identity transformative process, while 
the \#bpd group seemed to be still at the point at which identity was diagnosis-based.

With regards to the unexpected distinction related to empowerment, we note that this dimension significantly differentiates the two groups. In fact, contrary to our hypothesis, the empowerment dimension emerged only in \#bpdrecovery group. We did not expect this because of the online context, which has been strongly characterized as the empowerment and resistance to stigma (Naslund et al., 2014). However, our finding here suggests that empowerment is a complex task for BPD individuals in online settings as well, probably because it relates to the agency dimension that is particularly impaired in the borderline clinical population (Fonagy et al., 2015). Therefore, we can hypothesize that the empowerment dimension was linked to redefinition of the current identity, since a positive identity is the basis of the process of regaining power and assuming an agentive stance. On the other hand, we can hypothesize that the lack of empowerment dimensions in the \#bpd group may refer to another dynamic typical of BPD individuals (Zanarini, Frankenburg, Reich, \& Fitzmaurice, 2012): the tendency to delegate, which indicated a passive and non-agentive position.

The analysis also revealed that offline relationships had a supportive role for \#bpdrecovery individuals. This group showed a better capacity to recognize the supportive functions of others (peers, parents, etc.) in their PR process. In contrast, the \#bpd group seemed to devalue offline relationships and idealize online relationships. According to the literature, the perception of social support in relationships with family members and mental health professionals promotes PR in BPD individuals (Kverme, Natvik, Veseth, \& Moltu, 2019). Instead, we can hypothesize that within the online context, the \#bpd group enacted the typical splitting dynamics of BPD individuals who alternatively idealize and devalue others (Fertuck, Fischer \& Beeney, 2019; Gunderson et al., 2018).

In addition to differences, similarities also emerged between the two groups. As we expected, hope was a dimension that developed similarly in both groups as a motivational dimension that triggers and supports the PR process. To be able to take a PR path, being hopeful seems to be an essential first step for both groups, sine qua non. This is consistent with the literature on PR, which conceptualized hope as the first factor to emerge (Ridgway, 2001).

Contrary to expectations, another similarity was the lack of clear n.e. related to the meaning of life. This finding suggests, following Zanarini et al. (2012), that the addressing of this goal is extremely complex for individuals with BPD. The process of PR actually implies the effort to give new meaning and purpose to existence, in a personally authentic way (Anthony, 1993). Although the \#bpdrecovery group presented more dimensions of PR, the meaning of life is a more mature process in any recovery journey, and is uniquely complex for each BPD individual.

In summary, beyond the similarities between the two groups, findings seem to suggest that the two groups were in different steps of their PR process.

Moreover, these results suggest that the SSN may become an environment in which to enact dynamics related to psychopathology (D'Arienzo, Boursier \& Griffiths, 2019; Gargiulo \& Margherita, 2019) - but it can also be a "gym," a training arena for the development of some abilities and psychic functions (Boursier, Manna, Gioia, Coppola \& Venosa, 2018).

With regards to the CRF analysis, findings confirmed our second hypothesis: the \#bpdrecovery group presented a significantly higher reflective style. It is important to note that since the CRF software does not provide a cutoff for high RF per se, we could not say that the \#bpdrecovery group showed a high RF in absolute terms; we could only state that in this group a higher reflective style emerged in comparison with the other. So, we could hypothesize that in the \#bpdrecovery group there was a kind of emerging capacity to reflect on one's experience. This emerging capacity may be linked to greater autobiographical narrative competence (Esposito, Passeggia, Cutolo, Karterud \& Freda, 2020; Freda \& Esposito, 2016) emerging in the posts of the \#bpdrecovery group. If experiences are subjected to a mentalizing process, narratives become richer and more complex. In fact, through a narrative, one can share and verbalize emotional experiences, thereby facilitating explicit mentalizing (Esposito \& Freda, 2016; Esposito, Ribeiro, Gonçalves \& Freda, 2017). The \#bpdrecovery group seemed to be able to describe and label what is going on with greater narrative coherence. This is consistent with literature that states that RF promotes the coherence of self-narratives (Bateman \& Fonagy, 2012).

To conclude, based on these findings, we can hypothesize that this emerging RF, marked by CRF High index, may be associated with some functional dimensions of $\mathrm{PR}$ in the \#bpdrecovery group, such as identity redefinition, individual and social empowerment, and supportive connections, including offline. According to the literature (e.g., Bateman \& Fonagy, 2012), RF is involved in the process of redefining identity; thus, in our sample, an emerging RF capacity may have supported more adaptive dimensions of rebuilding users' identities. Furthermore, as RF is also involved in promoting an agentive sense of self and in recognizing oneself as an intentional author of one's actions (Bateman \& Fonagy, 2011), we could also hypothesize that the difference between the two groups in terms of empowerment may be sustained by the emerging capacity to reflect on one's (and others') experiences. Finally, as empathy is a necessary component of RF (Fonagy, Luyten \& Bateman, 2015), its development may have impacted the quality of \#bpdrecovery group relationships.

\section{Conclusions}

This study can be considered a first attempt to investigate the relationship between RF and the PR process on 
online platforms for users of social media platforms with BPD. Specifically, this study had two innovative objectives: to increase the understanding of PR in BPD individuals by considering the role of RF in promoting PR; and, as previously qualitative research only focused on face-to-face narratives or interviews collected in the context of mental health services, this study analyzed PR processes in online text posts shared by users with BPD on social media platforms.

We believe that an interesting implication of this study is that PR in BPD users may be considered a developmental process with several discrete steps. The CHIME dimensions (Leamy et al., 2011) are typically considered as independent dimensions of PR. It's plausible to hypothesize, instead, that the CHIME dimensions follow a developmental trend that could be associated with emerging RF in BPD users. For example, as hope and optimism emerged in both groups, they may be a preliminary dimension of the PR process; we can also hypothesize that the meaning of life, which did not emerge in either group, is the last step - an outcome resulting from relationships between the previous four CHIME dimensions. If this hypothesis is confirmed by further studies, it may contribute to a theoretical reconceptualization of the PR process in BPD individuals.

Regarding the methodological implications, we believe that the integration of stylistic and thematic analyses allows researchers to overcome the constraints of each analysis and to strengthen their resources by achieving a better understanding of the complexity of the phenomena under study. The stylistic approach, by itself, allows to reduce the complexity of the narrative data, but at the same time, its use limits the possibility to analyze the meaningmaking processes that occur in the narratives. By combining the stylistic with the thematic approach, we were able to study two different dimensions of narratives: the complexity of narrative content (what is narrated), which can be detected through qualitative thematic analysis, and the reflective style, namely the states or psychological functions underlying the language (how is narrated), which is better detected by the calculation of the frequency of some reflective quantitative indexes, provided by the stylistic analysis.

Regarding the clinical implications, we believe that the symptomatic identity, the lack of empowerment, and the splitting dynamics that characterize relationships in the \#bpd group point to the need for a clinical treatment that focuses on these PR dimensions, which were highly impaired in BPD individuals. Moreover, the clinical practice may consider what is shared by borderline individuals on social networks, in order to develop interventions that potentially integrate the online context as an important dimension of clients' lives. It also seems plausible that the Mentalization-Based Treatment would be an effective intervention even in the online context, as it may enhance the impaired mentalizing ability in BPD users and support PR processes.
Nevertheless, we acknowledge several limitations. The main limitation is the size of our sample. In future studies, it would be necessary to extend the sample to ensure that these results can be generalized. Moreover, the sample was rather homogeneous in terms of gender; thus, in future studies, it would also be useful to include more males in order to have the potential to reveal any gender differences that might exist. It is important to emphasize that these findings can be generalized only to users who explicitly identify themselves as BPD individuals on social media platforms; thus, findings cannot be extended to the general BPD population. Furthermore, it was difficult to recruit the participants on a platform like Instagram: we solicited 35 users who met the inclusion criteria, and we received agreement only from 14 of them. The low rate of agreement leads us to reflect on the difficulties that one may encounter when online research is conducted with clinical population, such as this one.

Despite the relevance of the hashtag in online research (Daer, Hoffman \& Goodman, 2014), the hashtag is only the initial selection criterion for participants. Although we followed the Coppersmith's method (2015), the hashtags we used cannot take into account the complexity of the hashtags that users with BPD diagnosis can use to narrate their recovery process. In future studies, it would be useful to use other criteria relevant to SSN research (e.g., photos, nicknames). Despite the cross-cultural applicability of the CHIME framework (Brijnath, 2015), to our knowledge, there have been no studies that used the CHIME framework in an online setting. The lack of socio-cultural data (e.g., nationality, education, etc.) and relevant information about the specific recovery journey of the users (how long they have been using the mental health services, their employment status, etc.) constituted an important limitation that might have affected results. In future studies, it would be useful to collect any socio-cultural data about users that could be relevant to understanding PR in BPD individuals. For the same reasons, it would be useful to collect data about the severity of the illness as well (e.g., age, comorbidities, etc.), since this would help distinguish borderline users, as the self-referred diagnosis does not allow one to infer it.

Therefore, it is important to highlight that the CRF criterion validity should be considered cautiously, as the validation sample was relatively small. Moreover, another limitation of the CRF is that it was based only on lexical elements; thus, the measure may be affected by IQ or verbal fluency (Boldrini et al., 2017). Finally, this is the first time that the CRF has been applied to text data from an online context, so further studies are needed to assess the reliability of the software on this kind of qualitative data. However, the applicability of the CRF to online texts has been suggested by the focus on a theme common in the answers of the AAIs used for the dictionary's validation and in the posts of this study. Furthermore, the CRF software produces an output that refers to the reflective style 
that, according to the authors, should be considered only one of the indicators of reflective function. On its own, however, this result cannot explain the complexity of the psychic functions of mentalizing. In future studies, combining CRF software with other measures of RF may allow us to explore the involvement of the different dimensions of mentalizing in the PR process.

\section{References}

Adler, N. (2017) Who Posts Selfies and Why? Personality, Attachment Style, and Mentalization as Predictors of Selfie Posting on Social Media (Doctoral dissertation, Cuny University of New York).

Allen, J. G., Fonagy, P., \& Bateman, A. W. (2008). Mentalizing in clinical practice. Washington, DC: American Psychiatric Press.

American Psychiatric Association (APA). (2013). Diagnostic and statistical manual of mental disorders (DSM-5®). Arlington, VA: American Psychiatric Publishing.

Andalibi, N., Ozturk, P., \& Forte, A. (2015). Depression-related Imagery on Instagram. In: Proceedings of the 18th ACM Conference Companion on Computer Supported Cooperative Work \& Social Computing - CSCW'15 Companion. Doi:10.1145/2685553.2699014

Anthony W. A. (1993). Recovery from mental illness: The guiding vision of the mental health service system in the 1990s. Psychosocial Rehabilitation Journal, 16(4), 11-23. Doi: 10.10372/095655

Antonsen, B. T., Johansen, M. S., Rø, F. G., Kvarstein, E. H., \& Wilberg, T. (2016). Is reflective functioning associated with clinical symptoms and long-term course in patients with personality disorders? Comprehensive Psychiatry, 64, 46-58. Doi: 10.1016/j.comppsych.2015.05.016

Article 13, General Data Protection Regulation, 679/2016.

Bateman, A. W., \& Fonagy, P. (2004). Mentalization-based treatment of BPD. Journal of Personality Disorders, 18(1), 3651. Doi: 10.1521/pedi.18.1.36.32772

Bateman, A., \& Fonagy, P. (2008). 8-year follow-up of patients treated for borderline personality disorder: mentalizationbased treatment versus treatment as usual. American Journal of Psychiatry, 165(5), 631-638. Doi: 10.1176/appi.ajp.2007. 07040636

Bateman, A. W., \& Fonagy, P. (2012). Handbook of mentalizing in mental health practice. Washington, DC: American Psychiatric Publishing.

Birnbaum, M. L., Rizvi, A. F., Correll, C. U., Kane, J. M., \& Confino, J. (2017). Role of social media and the Internet in pathways to care for adolescents and young adults with psychotic disorders and non psychotic mood disorders. Early intervention in psychiatry, 11(4), 290-295. Doi:10.1111/eip. 12237

Bogolyubova, O., Upravitelev, P., Churilova, A., \& Ledovaya, Y. (2018). Expression of Psychological Distress on Instagram Using Hashtags in Russian and English: A Comparative Analysis. SAGE Open, 8(4), 1-9. Doi: 2158244018811409.

Boldrini, T., Nazzaro, M. P., Damiani, R., Genova, F., Gazzillo, F., \& Lingiardi, V. (2018). Mentalization as a predictor of psychoanalytic outcome: An empirical study of transcribed psychoanalytic sessions through the lenses of a computerized text analysis measure of reflective functioning. Psycho- analytic Psychology, 35(2), 196. Doi: 10.1037/pap0000154

Borg, M., \& Davidson, L. (2008). The nature of recovery as lived in everyday experience. Journal of mental health, 17(2), 129-140. Doi: 10.1080/09638230701498382

Boursier, V., \& Manna, V. (2018). Selfie expectancies among adolescents. Construction and validation of an instrument to assess expectancies toward selfies among boys and girls. Frontiers in psychology, 9, 839. Doi: 10.3389/fpsyg. 2018.00839

Boursier, V., Manna, V., Gioia, F., Coppola, F., \& Venosa, N. (2018). Cyber-moms facing motherhood: Holding functions and regressive movements in parenting websites. In: Sekalala, S., Niezgoda B. C. (Eds.), Innovations in Global Prospective on Health Communication in the Age of Social Media (pp. 29-58). Doi: 10.4018/978-1-5225-3716-8

Brijnath, B. (2015). Applying the CHIME recovery framework in two culturally diverse Australian communities: Qualitative results. International Journal of Social Psychiatry, 61(7), 660-667. Doi: 10.1177/0020764015573084

British Psychological Society (2013). Ethics guidelines for internet-mediated research. Leicester, UK: British Psychological Society.

Cohen, J. (1960). A coefficient of agreement for nominal scales. Educational \& Psychological Measurement, 20(1), 37-46. Doi: 10.1177/001316446002000104

Coppersmith, G., Dredze, M., Harman, C., \& Hollingshead, K. (2015). From ADHD to SAD: Analyzing the language of mental health on Twitter through self-reported diagnoses. In: Proceedings of the 2nd Workshop on Computational Linguistics and Clinical Psychology: From Linguistic Signal to Clinical Reality. 1-10. The AAAI Press. Doi: 10.3115/v1/ W15-1201

Corrigan, P. W. (2002). Empowerment and serious mental illness: Treatment partnershipsand community opportunities. Psychiatric Quarterly, 73(3), 217-228. Doi: 10.1023/A: 1016040805432

Corrigan, P. W., \& Phelan, S. M. (2004). Social support and recovery in people with serious mental illnesses. Community Mental Health Journal, 40(6), 513-523. Doi: 10.1007/s 10597004-6125-5

D’Arienzo, M. C., Boursier, V., \& Griffiths, M. D. (2019). Addiction to social media and attachment styles: a systematic literature review. International Journal of Mental Health and Addiction, 17(4), 1-25. Doi: 10.1007/s11469-01900082-5

Daer, A. R., Hoffman, R., \& Goodman, S. (2014). Rhetorical functions of hashtag forms across social media applications. In: Proceedings of the 32nd ACM International Conference on The Design of Communication CD-ROM. ACM. Doi: $10.1145 / 2666216.2666231$

Denzin, N. K., \& Lincoln, Y. S. (2005). The SAGE handbook of qualitative research. Thousand Oaks: Sage.

De Meulemeester, C., Vansteelandt, K., Luyten, P., \& Lowyck, B. (2018). Mentalizing as a mechanism of change in the treatment of patients with borderline personality disorder: A parallel process growth modeling approach. Personality Disorders: Theory, Research, and Treatment, 9(1), 22-29. Doi: 10.1037/per0000256

Esposito, G., \& Freda, M.F. (2016). Reflective and agentive functions of narrative writing: a qualitative study on the narratives of university students. Integrative Psychological and Behavioral Science, 50, 333-357. Doi: 10.1007/s12124-0159323-5 
Esposito, G., Ribeiro, A.P., Gonçalves, M.M., Freda, M.F. (2017). Mirroring in Group Counseling: Analyzing Narrative Innovations. Small Group Research, 48(4), 1-29. Doi:10.1177/10464964176971491238789.

Esposito, G., Passeggia, R., Cutolo, A. S., Karterud, S., Freda, M.F. (2020). Treatment Integrity and Members' Change in Group Counseling: A Pilot Study on Counselor's Mentalizing Intervention. Professional Psychology: Research and Practice, in press. Doi: 10.1037/pro0000304

Estroff, S. E., Lachicotte, W. S., Illingworth, L. C., \& Johnston, A. (1991). Everybody's got a little mental illness: Accounts of illness and self among people with severe, persistent mental illnesses. Medical Anthropology Quarterly, 5(4), 331369. Doi: 10.1525/maq.1991.5.4.02a00030

Fertuck, E. A., Fischer, S., \& Beeney, J. E. (2019). Social cognition and Borderline Personality Disorder: Splitting and trust impairment Findings. Psychiatric Clinics of North America, 41(4), 613-632. Doi: 10.1016/j.psc.2018.07.003

Fertuck, E. A., Mergenthaler, E., Target, M., Levy, K. N., \& Clarkin, J. F. (2012). Development and criterion validity of a computerized text analysis measure of reflective functioning. Psychotherapy Research, 22(3), 298-305. Doi:10.1080/10503307.2011.650654

Fonagy, P., \& Bateman, A. (2008). The development of borderline personality disorder. A mentalizing model. Journal of Personality Disorders, 22(1), 4-21. Doi: 10.1521/pedi.2008.22.1.4

Fonagy, P., Bateman, A., \& Bateman, A. (2011). The widening scope of mentalizing: A discussion. Psychology and Psychotherapy: Theory, Research and Practice, 84(1), 98-110. Doi: 10.1111/j.2044-8341.2010.02005.x

Fonagy, P., \& Luyten, P. (2009). A developmental, mentalizationbased approach to the understanding and treatment of borderline personality disorder. Development and Psychopathology, 21(4), 1355-1381. Doi: 10.1017/S0954579409990198.

Fonagy, P., Luyten, P., \& Bateman, A. (2015). Translation: Mentalizing as treatment target in borderline personality disorder. Personality Disorders: Theory, Research, and Treatment, 6(4), 380. Doi: 10.1037/per0000113

Fonagy, P., Target, M., Steele, H., \& Steele, M. (1998). Reflective-functioning manual, version 5.0, for application to adult attachment interviews. London: University College London.

Freda, M.F., Esposito, G. (2016). Promoting reflection and reflexivity through narrative devices: Narrative Mediation Path qualitative multimodal method. Qualitative Research Journal, 17(1), 2-19. Doi: 10.1108/QRJ-06-2016-0039.

Freda, M. F., \& Esposito, G. (2020). Commentary: The role of mediational devices in promoting mentalizing. Clinical Psychology: Science \& Practice, 2020;00e12371. Doi: $10.1111 / \mathrm{cpsp} .12371$

Freda, M.F., Esposito, G., Quaranta, T. (2015). Promoting Mentalization in Clinical Psychology at Universities: A Linguistic Analysis of Student Accounts. Europe's Journal of Psychology, 11(1), 34-49. Doi: 10.5964/ejop.v11i1.812.

Freda, M.F., Gonzàlez-Monteagudo, J., Esposito, G. (2016) (Eds). Working with Underachieving Students in Higher Education: Fostering Inclusion through Narration and Reflexivity. Abingdon: Oxon; New York: NY; Routledge. Doi: $10.4324 / 9781315659121$

Freeman, C. (2016). What is mentalizing? An overview. British Journal of Psychotherapy, 32(2), 189-201. Doi: 10.1111/bjp. 12220

Gagliardini, G., Gullo, S., Caverzasi, E., Boldrini, A., Blasi, S., \& Colli, A. (2018). Assessing mentalization in psychother- apy: first validation of the Mentalization Imbalances Scale. Research in Psychotherapy: Psychopathology, Process and Outcome, 21(3), 164-177. Doi: 10.4081/ripppo.2018.339

Gargiulo, A., \& Margherita, G. (2019). Narratives of Self-harm: the experience of young women through the qualitative analysis of blogs. Mediterranean Journal of Clinical Psychology, 7(1), 1-19. Doi: 10.6092/2282-1619/2019.7.2055

George, C., Kaplan, N., \& Main, M. (1996). The Adult Attachment Interview. Unpublished manuscript. Department of Psychology, University of California at Berkeley.

Gunderson, J. G., Herpertz, S. C., Skodol, A. E., Torgersen, S., \& Zanarini, M. C. (2018). Borderline personality disorder. Nature Reviews Disease Primers, 4(1), 1-20. Doi: h10.1038/nrdp.2018.29

Holm AL, \& Severinsson, E. (2011). Struggling to recover by changing suicidal behaviour: Narratives from women with borderline personality disorder. International Journal of Mental Health Nursing, 20(3), 165-173. Doi: 10.1111/j. 1447-0349.2010.00713.x

Hu, Y., Manikonda, L., \& Kambhampati, S. (2014). What we instagram: A first analysis of instagram photo content and user types. In: Proceedings of the 8th International Conference on Weblogs and Social Media, ICWSM 2014 (pp. 595-598). The AAAI Press.

Jiang, L. C., Bazarova, N. N., \& Hancock, J. T. (2011). The disclosure-intimacy link in computer-mediated communication: An attributional extension of the hyperpersonal model. Human Communication Research, 37(1), 58-77. Doi: 10.1111/j.1468-2958.2010.01393.x

Jinnie, O., Michael, J., Sakari, L., Butterfill, S., \& Lukasz, W. (2020). Interpersonal functioning in borderline personality disorder traits: a social media perspective. Scientific Reports, 10(1), 1-8. Doi: 10.1038/s41598-020-58001-x

Katsakou, C., Marougka, S., Barnicot, K., Savill, M., White, H., Lockwood, K., \& Priebe, S. (2012). Recovery in borderline personality disorder (BPD): A qualitative study of service users' perspectives. PLoS One, 7(5) Doi: 10.1371/journal. pone. 0036517

Kverme, B., Natvik, E., Veseth, M., \& Moltu, C. (2019). Moving toward connectedness - a qualitative study of recovery processes for people with borderline personality disorder. Frontiers in psychology, 10:430. Doi: 10.3389/fpsyg. 2019.00430

Khosravinik, M., \& Unger, J. W. (2016). Critical discourse studies and social media: Power, resistance and critique in changing media ecologies. In: Wodak R. \& Meyer M. (Eds.) Methods of Critical Discourse Studies, pp. 205-233. Thousand Oaks, CA: Sage.

Kingod, N., Cleal, B., Wahlberg, A., \& Husted, G. R. (2016). Online peer-to-peer communities in the daily lives of people with chronic illness. Qualitative Health Research, 27(1), 8999. Doi: $10.1177 / 1049732316680203$

Konnelly, A. (2015). \#Activism: identity, affiliation, and political discourse-making on Twitter. The Arbutus Review, 6(1), 1-16. Doi: 10.18357/ar.konnellya.612015

Lamarre, A., \& Rice, C. (2017). Hashtag recovery: \#eating disorder recovery on Instagram. Social Sciences, 6(3), 1-15. Doi: $10.3390 /$ socsci6030068

Larivière, N., Couture, É., Blackburn, C., Carbonneau, M., Lacombe, C., Schinck, S. A., David, P., \& St-Cyr-Tribble, D. (2015). Recovery, as experienced by women with borderline personality disorder. Psychiatric Quarterly, 86(4), 555-568. Doi:10.1007/s11126-015-9350-x 
Leamy, M., Bird, V., Le Boutillier, C., Williams, J., \& Slade, M. (2011). Conceptual framework for personal recovery in mental health: systematic review and narrative synthesis. The British Journal of Psychiatry, 199(6), 445-452. Doi:10.1192/bjp.bp.110.083733

Levy, K. N., Meehan, K. B., Kelly, K. M., Reynoso, J. S., Weber, M., Clarkin, J. F., \& Kernberg, O. F. (2006). Change in attachment patterns and reflective function in a randomized control trial of transference-focused psychotherapy for borderline personality disorder. Journal of Consulting and Clinical Psychology, 74(6), 1027-1040. Doi: 10.1037/0022006X.74.6.1027

Liotti, G., \& Gilbert, P. (2011). Mentalizing, motivation and social mentalities: Theoretical considerations and implications for psychotherapy. Psychology and Psychotherapy: Theory, Research and Practice, 84, 9-25. Doi: 10.1348/14760831 0X520094

Maone, A., \& D’Avanzo, B. (2015). Recovery. Nuovi paradigmi per la salute mentale [Recovery. New paradigms for mental health]. Milano: Raffaello Cortina Editore.

MacIntosh, H. B. (2017). Measuring reflective functioning in psychoanalytic psychotherapy. International Journal of Psychoanalysis and Education, 9(1), 5-21. http://www.psychoedu.org/index.php/IJPE/article/view/ 188

Margherita, G., \& Gargiulo, A. (2018). A comparison between pro-anorexia and non-suicidal self-injury blogs: From symptom-based identity to sharing of emotions. Psychodynamic Practice, 24(4), 346-363. Doi:10.1080/14753634.2018. 1535326

Mergenthaler, E. (1996). Emotion-abstraction patterns in verbatim protocols: A new way of describing psychotherapeutic processes. Journal of Consulting and Clinical Psychology, 64(6), 1306-1315. Doi:10.1037/0022-006X.64.6.1306

Mergenthaler, E., \& Bucci, W. (1999). Linking verbal and nonverbal representations: Computer analysis of referential activity. British Journal of Medical Psychology, 72(3), 339-354. Doi: 10.1348/000711299160040

Muller, C., G. Overbeck, \& R. Grabhorn. (2006), The importance of RF to the diagnosis of psychic structure. Psychology and Psychotherapy: Theory, Research and Practice, 79, 485-494. Doi: 10.1348/147608305x68048

Naslund, J. A., Aschbrenner, K. A., Marsch, L. A., \& Bartels, S. J. (2016). The future of mental health care: peer-to-peer support and social media. Epidemiology and Psychiatric Sciences, 25(2), 113-122. Doi: 10.1017/S2045796015001067

Naslund, J. A., Aschbrenner, K. A., McHugo, G. J., Unützer, J., Marsch, L. A., \& Bartels, S. J. (2019). Exploring opportunities to support mental health care using social media: A survey of social media users with mental illness. Early Intervention in Psychiatry, 13(3), 405-413. Doi: 10.1111/ eip. 12496

Naslund J. A., Grande S. W., Aschbrenner K. A., \& Elwyn G. (2014). Naturally occurring peer support through social media: the experiences of individuals with severe mental illness using YouTube. PLoS One, 9(10). Doi:10.1371/journal.pone. 0110171

Ng, F. Y., Bourke, M. E., \& Grenyer, B. F. (2016). Recovery from borderline personality disorder: a systematic review of the perspectives of consumers, clinicians, family and cares. PLoS One, 11(8). Doi: 10.1371/journal.pone.0160515

Oldmeadow, J. A., Quinn, S., \& Kowert, R. (2013). Attachment style, social skills, and Facebook use amongst adults. Computers in Human Behavior, 29(3), 1142-1149. Doi: 10.1016/ j.chb.2012.10.006

Olszanowski, M. (2015). The 1x1 common: The role of Instagram's hashtag in the development and maintenance of feminist exchange. In N. Rambukkana (Ed.), Hashtag Publics: The Power and Politics of Discursive Networks (pp. 229242). New York, NY: Peter Lang.

Piat, M., Seida K., \& Sabetti J. (2017) Understanding everyday life and mental health recovery through CHIME. Mental Health and Social Inclusion, 21(5), 271-279. Doi:10.1108/MHSI-08-2017-0034

Pillai, A. M. (2019). Image vs. text in narratives: The case study of National Geographic's Instagram (Doctoral dissertation, Dublin Business School).

Potthoff, P., \& Moini-Afchari, U. (2014). Mentalization-based treatment in groups-a paradigm shift or old wine in new skin?. Group Analysis, 47(1), 3-16. Doi:10.1177/ 0533316413518488

Reece, A. G., \& Danforth, C. M. (2017). Instagram photos reveal predictive markers of depression. EPJ Data Science, 6(1), 15. Doi: 10.1140/epjds/s13688-017-0110-z

Ridgway, P. (2001). ReStorying psychiatric disability: Learning from first person recovery narratives. Psychiatric Rehabilitation Journal, 24(4), 335-343. Doi:10.1037/h0095071

Shepherd, A., Sanders C., Doyle, M., \& Shaw, J. (2016). Personal recovery in personality disorder: systematic review and meta-synthesis of qualitative methods studies. International Journal of Social Psychiatry, 62(1), 41-50. Doi: 10.1177/0020764015589133

Slade, M. (2009). Personal recovery and mental illness: A guide for mental health professionals. Cambridge: Cambridge University Press.

Smahelova, M., Drtilova, H., Smahel, D., \& Cevelicek, M. (2019). Internet Usage by Women with Eating Disorders during Illness and Recovery. Health Communication, 19, 19. Doi: 10.1080/10410236.2019.1582135

Topor, A., Borg, M., Di Girolamo, S., \& Davidson, L. (2011). Not just an individual journey: Social aspects of recovery. International Journal of Social Psychiatry, 57(1), 90-99. Doi: 10.1177/0020764009345062

Turel, O., He, Q., Brevers, D., \& Bechara, A. (2018) Social networking sites use and the morphology of a social-semantic brain network. Social Neuroscience, 13(5), 628-636. Doi: 10.1080/17470919.2017.1382387

Zanarini, M. C., Frankenburg, F. R., Reich, D. B., \& Fitzmaurice, G. (2012). Attainment and stability of sustained symptomatic remission and recovery among patients with borderline personality disorder and axis II comparison subjects: a 16-year prospective follow-up study. American Journal of Psychiatry, 169(5), 476-483. Doi: 10.1176/appi. ajp.2011.11101550 